\title{
A comprehensive examination of ACE-2 receptor and prediction of spike glycoprotein and ACE-2 interaction based on in silico analysis of ACE-2 receptor
}

\author{
Nehir Özdemir Özgentürk ${ }^{1}$ and EMRE Aktaş ${ }^{1}$ \\ ${ }^{1}$ Yildiz Technical University
}

September 13, 2021

\begin{abstract}
ACE-2 receptor plays a vital role not only in the SARS-CoV-induced epidemic but also in some diseases. Studies have been carried out on the interactions of ACE-2- SARS-CoV proteins. However, comprehensive research has not been conducted on ACE2 protein by using bioinformatic tools. The present study especially two places, G104 and L108 points, which are effective in protecting the structure of the ACE-2 protein, play a critical role in the biological functioning of this protein, and play an essential role in determining the chemical-physical properties of this protein, and play a crucial role for ACE-2 protein-SARS CoV surface glycoprotein, were determined. It was also found that the G104 and L108 regions were more prone to possible mutations or deletions than the other ACE-2 protein regions. Moreover, it was determined that all possible mutations or deletions in these regions affect the chemical-physical properties, biological functions, and structure of the ACE-2 protein. Having a negative GRAVY value, one transmembrane helix, a significant molecular weight, a long-estimated half-life as well as most having unstable are results of G104 and L108 points mutations or deletions. Finally, it was determined that LQQNGSSVLS, which belong to the ACE-2 protein, may play an active role in binding the spike protein of SARS-CoV. All possible docking score results were estimated. It is thought that this study will bring a different perspective to ACE-2 _SARS-CoV interaction and other diseases in which ACE-2 plays an important role and will also be an essential resource for studies on ACE-2 protein.
\end{abstract}

\section{Hosted file}

manuscriptwithfigure.docx available at https://authorea.com/users/433645/articles/537049a-comprehensive-examination-of-ace-2-receptor-and-prediction-of-spike-glycoprotein-andace-2-interaction-based-on-in-silico-analysis-of-ace-2-receptor 